\title{
Psychological Factors Affecting the Investment Decisions in the Promotion of Small and Medium Enterprises (SMEs) In Khyber Pakhtunkhwa
}

\author{
MIAN MUHAMMAD WASEEM IQBAL \\ Ph.D Scholar, Lecturer in Business Administration \\ Sarhad University of Science and Information Technology Peshawar, Pakistan. \\ Email: vaseemeqbal@gmail.com \\ Prof. Dr. S. GHIASUL HAQ \\ Dean, Faculty of Management Sciences \\ Sarhad University of Science and Information Technology Peshawar, Pakistan. \\ LAL MUHAMMAD \\ Lecturer in Business Administration \\ Sarhad University of Science and Information Technology Peshawar, Pakistan.
}

\begin{abstract}
Many authors have recognised that psychological factors influence the decision making of investors in the stock market. However, the SMEs sector always overlooked, but it plays an essential role in economic upsurge. The prime purpose of the current study is to investigate the influence of psychological factors such as confidence, optimism, loss aversion and herding behaviour could affect investment decisions in KP's SMEs. The pilot study carried out initially. The study surveyed 249 samples through simple random technique through self-administrative questionnaires as previously no questionnaire available. The reliability of the questionnaire is 0.71 Cronbach's Alpha Static and validity of the questionnaire is checked through Exploratory Factor Analysis (EFA). The study uses the descriptive statics, frequency and binary logistic regression used. The mean value of psychological factors is 3.81 shows a high impact on investment decisions, with 66\% of investors has shown positive concern over psychological factors and considering it motivational factor for investment decisions. The result binary logistic model revealed that all sub-factors of psychological are positively significant with investment decision except the loss aversion. The probability of investing in the presence of confidence (79.59\%), optimism (89.90\%), loss aversion (64.29\%), herd behaviour (88.37\%) and overall psychological factors (80.54\%) in KP's SMEs. Hence it can be concluded that investors are rational and their investment decisions in SME's at times influence by psychological factors.
\end{abstract}

Keywords: SMEs, Confidence, Optimism, Loss Aversion, Herding Behaviour, Psychological Factors.

\section{Introduction}

Behaviour finance deals with the psychology of the human perspective of decision-making and inclined to intellective illusions (Ritter, 2003). The decision-making is a complicated process and influenced by course of action, which results in different findings. Kengatharan and Kengatharan (2014) have pointed out that psychological behaviour significantly influences the investor's behaviour. Investment is a capital that is invested with the expectation that it will generate profit in future. Firms raise the finances from internal and external sources for new investments in order to enhance the production capacity. The impact of investment 
decisions is explained by behaviour theories such as prospect; heuristic and herding that reflect the overall picture. The personality of every investor is different from others because of different ethos but usually base their investment decisions on objectives, profitability and risk associated with it (Gakhar, 2019).

Different authors have taken different psychological factors in relation to investment decisions. Overconfidence influences their own decisions as a result of mood, feelings, intuition and emotion and consider their results rational and seek evidence to support their viewpoint and neglect the contradicting evidence. Qadri \& Shabbir (2014); Qureshi, Rehman, \& Hunjra (2014) and Bashir, Azam, Butt, Javed, \& Tanvir (2013) have found that overconfidence influence the investor's investment decisions significantly positive, but the studies of Kafayat (2014) and Kengatharan \& Kengatharan (2014) showed a negative relationship between overconfidence and decision making. Confident investors trade more than less confident investors (Hoffmann \& Post, 2016). Kahneman \& Tversky (1979) proposed a theory of prospects that people rely on loss aversion while making decisions and do not value the gain and loss likewise.

Most importantly, loss aversion bias has a considerable impact on investment decisions and makes an investor stagnant (Bakara \& Yia, 2016). Investors are rigid to any change in their portfolio and cause status quo bias by loss aversion. Hassan, Khalid, \& Habib (2014) found that the impact of some biases such as overconfidence has a significant effect but has loss aversion been insignificant with investment decision in Pakistani investors. In financial economics, optimism has comparatively slightly steer sign on individual economic decision-making (Puri \& Robinson, 2007). Optimism is the implicit origin of many economic phenomena and crucial portion of economic decision-making. It reflects both macroeconomic and microeconomic activity as it involves high stake decisions like startup investment and investment behaviour (Iqbal, 2015). Puri \& Robinson (2007) mentioned the influence of optimism with decision making as it involves savings decisions and portfolio choice. Herding behaviour relates to "follow the leader" mindset and believes that decision made by leader/majority are always appropriate. In herding behaviour, individuals base their decisions on the majority actions, and that makes stock market inefficient; because of creating speculative bubbles due to buying and selling (Luong \& $\mathrm{Ha}, 2011$ ). Herding behaviour is more common in institutional investors than individual investors (Hirt \& Block, 2012). Wamae (2013) and Kengatharan \& Kengatharan (2014) found herding significantly positive with an individual's investment decisions.

In Pakistan, SMEs play an essential role in the economic growth, the progression of technological innovation, sourcing from large industries, support to cottage industries, and promoting economic growth and social development (Dar, Ahmed, \& Raziq, 2017). SMEs play in indispensable role in creating such economic activity and rapid industrialisation of any country. In developing countries, the role of SME's is comparatively more significant where technology, skilled labour, proper infrastructure and essential utilities are often not available. SMEs contribute significantly in economic development and creating economic competitiveness (Ahmad, Kassim, \& Rani, 2010; Schlogl, 2004) and boosting the economic growth of a country (Rohra \& Panhwar, 2009). The establishment of a small firms helps in the expansion of the business development by developing of new products, machines, utilising human resources required investments and firms faced hurdles in getting loans (Nichter \& Goldmark, 2009).Moreover, SMEs can create more entrepreneurs and can perform a significant role in the rapid industrialisation of a country. (Kuratko, Hornsby, \& Naffziger, 1997; Robichaud, McGraw, \& Roger, 2001) showed that the motivation of entrepreneurs has an impact on their business success and leads to their timely right investment decisions. Governments are making enormous efforts in developing SMEs; as a result, these enterprises contribute significantly in job creation, Human Resource Development (HRD) and GDP of a country (Kadiri, 2012). In large industrial economies, more workers are working in SMEs, and not in multinationals firms (Millinuex, 1997). In the 1970s and 1980s, the demand for low-cost industries has further increased due to the fundamental change in economic structure and development of new markets (Gveroski \& Jankuloska, 2017). (Khalique, Isa, Shaari, \& Ageel, 2011) have pointed out that the performance of Pakistan's economy is a direct reflection of the SME sector, like that of many developing countries. According to (Mukhtar, 2018) has concluded that SME. 
“.... not only their capacity to employ a disproportionately large number of people and boost economic growth that SME's provide an attractive solution to Pakistan's current economic problems, in particular, the youth unemployment."

Regardless of the importance of SMEs and its role in economic growth, this sector is not well organised and developed as compared to the developed and even many developing countries and required more attention because the available opportunities could not be utilised to an optimal level. The SMEs of Khyber Pakhtunkhwa (KP) on average contribute 14.3\% in Pakistan's GDP (Zafar \& Mustafa, 2017). As a whole in Pakistan and especially in KP's SMEs are not well organised and developed because the total volume of investment is much below than the available potential. There are several motivational factors that can influence the investment decision in SMEs, but the objective of the present study is to identify the psychological factors that can influence the investment decision in KP's SMEs.

\section{Literature Review}

\section{Investment Theories}

The fisher theory of investment focused on the efficiency of capital and future return. It was observed that an investor could continue its investment until the net present value become equal to the opportunity cost of the capital. The theory focused on capital and its alternative uses in order to make further investment. On the other hand, in keyn's theory, an investment can be made by comparing the profit margin in each investment made with the real interest rate. It was observed that when MEC exceeds $r$ then the investor continues its investment. In the accelerator approach, Keyne argued that investment could be made when profit increases due to an increase in production in the current periods. However, the inflexible accelerator theory focuses not only on the current period but also its lag value to adjust output and capital stock to increase profit and to attract investors. However, Tobin argued that investment is made by looking at the situation of the stock market. It usually takes place by looking at the prices of shares and interest rate fluctuation. According to Jorgenson theory net investment is equal to total investment and less replacement investment and it depends on the interest rate by comparing alternative capital accumulation. The above financial theories are related to economics, but the scope of the study is related to the motivational factors in investment decisions in SMEs.

\section{Theories of Investors' Behaviour}

There are many behaviours theories related to investment. Prospect Theory is a behavioural model of determination likelihood of gains or losses. Regret Theory deals with sentimental error in judgement made by people who take investment decisions. Theory of Mental Accounting states that its in human nature that they categorise information into different mental compartments in their mind and they retrieve the required information whenever it is required. Theory of Overconfidence is about a person's subjective confidence that investors usually consider their knowledge, experience and expertise superior while making decisions. Behavioural authors have found various evidence that investor's decision-making is not always rational but impact by errors and biases. Many authors have now researched investor behaviour and psychological biases that affect investment.

\section{Psychological Factors influence Investment Decisions}

Psychologists have found that any person's decision could be affected and influenced by unavoidable psychological, cognitive and emotional biases (Iqbal, 2015). Several studies have shown a relationship between the investor's investment decisions and psychological factors (for example, (Riaz, Hunjra, \& Azam, 2012)(Bakar \& Yia, 2016) (Boda \& Sunitha, 2018)(Riaz \& Ahmed, 2015)(Ghelichi, Nakhjavan, \& Gharehdaghi, 2016). The present study tries to identify the psychological factors of those investors who have invested in the last three year in KP's SMEs. Kengatharan and Kengatharan (2014) have pointed out 
that psychological behaviour significantly influences the investor's behaviour. In this study, the author has considered psychological factors, i.e. confidence, optimism, loss aversion and herd behaviour.

Confidence: Investors takes risks in order to generate more earning and confident about their decisionmaking. Ton \& Dao (2014) found that five factors of psychological factors, i.e. overconfidence, optimism, herd behaviour, the psychology of risk and pessimistic have an impact on investment decisions and overconfidence and herd behaviour have a negative impact while others have a positive impact. Alquraan, Alqisie, \& Shorafa (2016) overconfidence has a significant effect on investment decision in the Saudi Stock Market. Gill, Khurshid, Mahmood, \& Ali (2018) found a positive and significant relationship between overconfidence bias and economic expectations with investment decision making at Lahore Stock Exchange. Our study does not include overconfidence because it originates from optimism and optimism is includes in our study. Our study will include the confidence which was previously used with investor confidence with the stock market used by (Shalom, 2013). Faris (2019) surveyed 107 investors and found that excessive confidence and herd behaviour and excessive optimism statistically significant effect on the decision-making. This study will use confidence as a motivational factor in investment decision in the promotion of SMEs. The output of these variables will be something new to contribute. Our study will draw a series of questions covering every aspect of confidence. Base on this argument hypothesis are drawn.

Optimism: Optimism means that all will be better than the examination. People have positive feelings about everything. At the peak of optimism, investor greed moves stocks beyond their intrinsic value (Hong \& Stein, 1999). Faris (2019) surveyed 107 investors and found that optimism statistically significant effect on the decision-making. Gervais, Heaton, \& Odean (2002) found that optimistic managers undertake projects quickly. Thus moderately overconfident or optimistic managers take decisions that are in the better interest of shareholders than the ones taken by rational managers. Huang, Jui, Tan, Sulaeman, \& Faff (2018) found that optimism and over-precision have distinct impacts on investment decisions. Chen \& Lin (2013) found that underinvested firms with a CEO who has a higher level of managerial optimism can improve the firm's investment efficiency by reducing the degree of underinvestment, which further increases the firm's value. Ton \& Dao, (2014); Huang et al., (2018) optimism affect positively on long term investment of investors significantly. The present study will take optimism with investment decisions but in SMEs. Base on this argument, we draw the research hypothesis.

Loss Aversion: Investors do not want to bear the loss and afraid of losing. Richard (2002) mentioned that investors behave irrationally because they are afraid of losses in future. Kabra, Mishra, \& Dash (2010) finds out that even if there are chances of growth in the market, some investors even then invest according to the risk they can afford. Kisaka (2015) the study depicted that there is a significant positive relationship between loss aversion and stock investment. Sarwar \& Afaf (2016) has taken the loss aversion as one variable of their study and results show that it influences the decision making of the investors. Only one study is conducted on loss aversion with decision making. Our study will include loss aversion as no one did any study on investor loss aversion in investment decisions in KP's SMEs.

Herd Behaviour: Investors discuss their investment with their relatives and friends and want to act on it. Bikhchandani \& Sharma (2001) mentioned that some investors have the impact of others on their decision making instead of following their strategies and policies. Many authors have worked on herd behaviours with investment decisions. Huang et al., (2018) surveyed 422 investors and used logistic regression found a negative impact of herd behaviour on investment decisions of stock market investors. Abul (2019) worked on different psychological factors optimism, pessimism, herd behaviour, and risk appetite influenced the investment decision while herd behaviour has an insignificant effect with an investment decision (Areiqat, Abu-rumman, Al-alani, \& Alhorani, 2019). Faris (2019) surveyed 107 investors and found that excessive confidence and herd behaviour and excessive optimism statistically significant effect on the decisionmaking but Ton \& Dao (2014) results showed a significantly negative relationship between herd behaviour 
and investment decision. The finding of this study will add a new perspective to SMEs as previous studies all based on stock market investors. Base on this argument, we made our hypothesis.

\section{Research Hypothesis}

$\mathbf{H}_{\mathbf{1}}$ : Investment decision influenced significantly by psychological sub-factor confidence in KPs' SMEs.

$\mathbf{H}_{2}$ : Investment decision influenced significantly by psychological sub-factors optimism in KPs' SMEs.

$\mathbf{H}_{3}$ : Investment decision influenced significantly by psychological sub-factors loss aversion in KPs' SMEs.

$\mathbf{H}_{\mathbf{4}}$ : Investment decision influenced significantly by psychological sub-factors herd behaviour in KPs' SMEs.

\section{Theoretical Framework}

There are three main theories, i.e. Prospect Theory, Theory of Mental Accounting and Theory of Overconfidence. These theories highlight decision-making affected by the investor's value system. Investors compare their investment decisions results with other results and respond according to the loss or profit they made through their decisions (Kahneman \& Tversky, 1979). This study classified Psychological factor into four categories, i.e. confident, optimism, loss aversion and herd behaviour. Different work has been done on this particular subject by taking different determinants which investment decisions. Different researchers used different factors to analysed investment decision, but the current study takes four factors which are expected to affect investment decision in KP's SMEs. By the analysis of data and through general perception, it is believed that investment in KP's SMEs is quite lower as compared to other provinces of Pakistan. The theoretical framework given below depicts all factors affecting investment decision, so all can be treated equally.

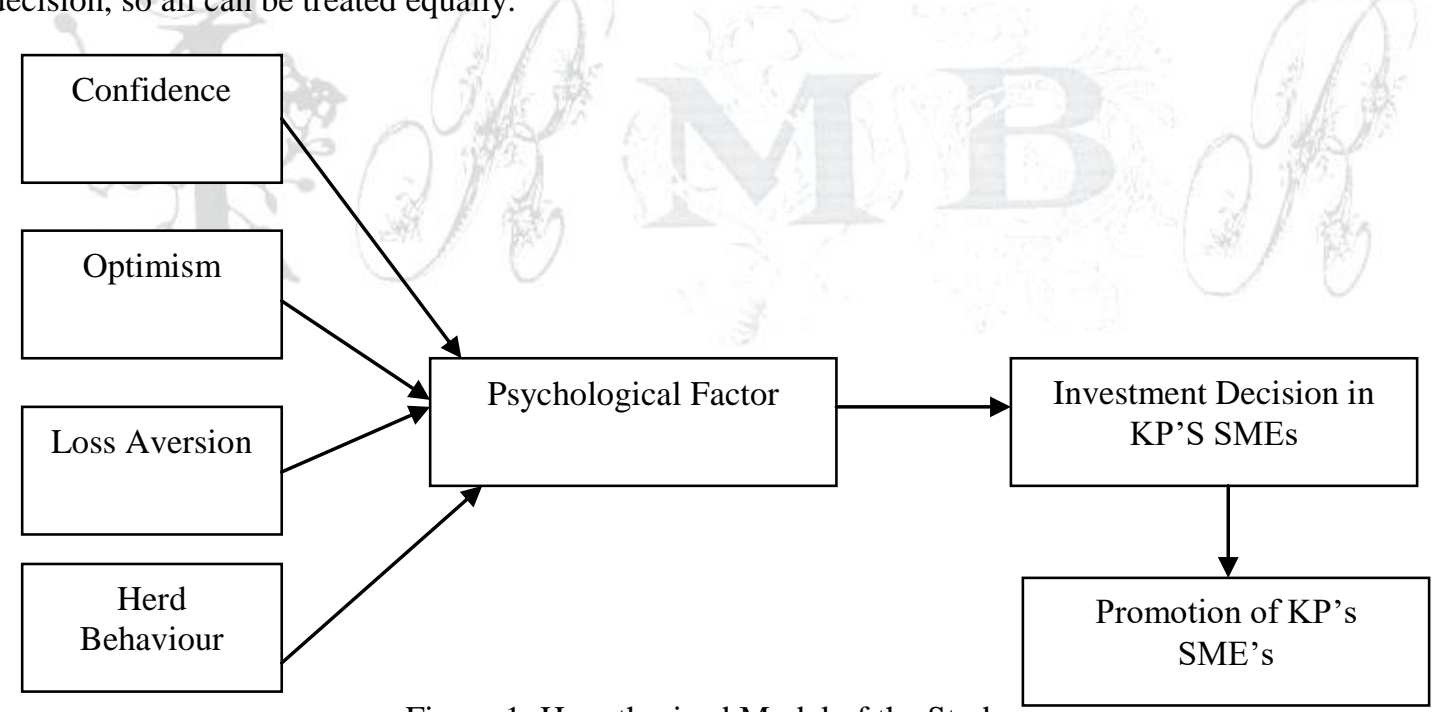

Figure 1: Hypothesized Model of the Study

\section{Research Methodology}

\section{Data Collection}

The research primarily focused on the primary sources of data collected through a self-develop research questionnaire based on a 5-Likert Scale. The population for this study is SMEs working in the industrial economic zone of KP. There are a total of 1286 firms registered with Khyber Pakhtunkhwa Economic Zone Development Company (KPEZDC) out of which 887 firms are currently functional and the remaining are either closed/in process/case. The firms working in Peshawar and Hattar region consist of 704, which 
constitute of 79.37, approximately $80 \%$ of total functional KP's firms. In this study, our target population is Peshawar and Hattar as it represents $80 \%$ of whole KP's SMEs. The sample is drawn 349 samples from the targeted population by using a (Cochran, 1963) sample size equation and used the most appropriate method of probability sampling, i.e. Simple Random Technique.

\section{Variables Description}

Investors are motivated by several factors to make investment decisions in SMEs, but our study is restricted to psychological factors. After reviewing the literature, we derived the number of variables that motivates the investors to invest and some variables are drawn based on logic. This study consists of four psychological factors, as shown in Table 1.

Table 1: Coding Scheme of Psychological Factors

\begin{tabular}{|c|c|c|}
\hline $\begin{array}{l}\text { Psychological } \\
\text { Sub Factors }\end{array}$ & Codes & Questions \\
\hline \multirow{6}{*}{$\begin{array}{l}\text { Confidence } \\
\text { (Ordinal Scale) }\end{array}$} & CON1 & Outperforming business skills motivate you to invest. \\
\hline & CON2 & You invest even if there is a risk to invest. \\
\hline & CON3 & Expert opinions motivate you to invest. \\
\hline & CON4 & Past investment experience motivates you to invest. \\
\hline & CON5 & Specialised in this kind of business motivates you to invest. \\
\hline & CON6 & Attractive business motivates you to make investment \\
\hline \multirow{4}{*}{$\begin{array}{l}\text { Optimism } \\
\text { (Ordinal Scale) }\end{array}$} & OPT1 & You easily adjust when things go wrong financially. \\
\hline & OPT2 & If you make a loss, you will quickly recover soon. \\
\hline & OPT3 & You are usually able to anticipate the trends of the market. \\
\hline & OPT4 & $\begin{array}{l}\text { When many businesses are going down, you believe the market will } \\
\text { recover soon. }\end{array}$ \\
\hline \multirow{3}{*}{$\begin{array}{l}\text { Loss Aversion } \\
\text { (Ordinal Scale) }\end{array}$} & LA1 & You are very careful while investing. \\
\hline & LA2 & You do not invest if the expected returns are down. \\
\hline & LA3 & You close your business in case of uncertainty in the market. \\
\hline \multirow{5}{*}{$\begin{array}{l}\text { Herd Behaviour } \\
\text { (Ordinal Scale) }\end{array}$} & & Other investor's decisions influence your investment decision. \\
\hline & & Other investors closing their business have an impact on your business. \\
\hline & HB3 & You consider information from friends/colleagues is more reliable. \\
\hline & HB4 & $\begin{array}{l}\text { Your investment is motivated when others are making a new } \\
\text { investment. }\end{array}$ \\
\hline & HB5 & $\begin{array}{l}\text { You do not make a new investment when other investors are closing } \\
\text { business. }\end{array}$ \\
\hline
\end{tabular}

\section{Results}

\section{Data Analysis}

It is a process and a plan of actions for qualitative data analysis. The author used a self-administrative questionnaire for qualitative data analysis by collecting the primary data. The author used different statistical methods and techniques to accomplished the objective of the study such as Descriptive Statistics (mean, standard error and frequencies in percentages), Cronbach's Alpha test, Factor Analysis, Logistic regression and best model selection method.

\section{Reliability and Validity}

The small size of 25 respondents (10\% of the sample) is used for a pilot study to check the questionnaire reliability and validity along with the purpose to check whether the mentioned hypothesis will be testified 
form the collected data through the self-developed questionnaire. The reliability of the questionnaire is checked through Cronbach's Alpha statistic (Cronbach, 1951), which is used to measure internal consistency. The reliability of the questionnaire is 0.76 for a pilot study, which is in the acceptable range. The validity of the questionnaire is checked through specialised expertise of the respective field and incorporated those changes suggested by an expert. The reliability collected for the sample size is 0.71 Cronbach's Alpha and validity is checked through the Exploratory Factor Analysis (EFA) as the questionnaire is self-administrated and Principal Component Analysis (PCA) method is used. Only two questions are excluded from herd behaviour due to low loading factor of 0.5 (Annexure 1).

\section{Frequency Distribution}

The questionnaire is consisting of two sections; the first section deals with general information and the second section is specific information which deals with questions related to psychological, motivational factors in investment decisions. Frequency distributions of the first section are given below.

Table 2: General Information of Frequency Distribution [n=249]

\begin{tabular}{|llll|}
\hline Questions & Options & Frequency & Percentage \\
\hline \multirow{2}{*}{ Nature of Organization } & Sole proprietorship & 77 & 30.9 \\
& Partnership & 172 & 69.1 \\
Nature of Business & Trading & 112 & 45 \\
& Manufacturing & 137 & 55 \\
& Less than one (1) year & 32 & 12.8 \\
Company Operations & Between 1 and 5 years & 73 & 29.3 \\
& Between 6 and 10 years & 109 & 43.7 \\
& Above 10 years & 35 & 14.2 \\
Numbers of Employees & Less than 50 employees & 164 & 65.9 \\
& More than 50 and less than & 60 & 24.1 \\
\hline
\end{tabular}

Table 2 shows the frequency distribution of the first part (general information). The nature of an organisation is divided into two different categories as mostly KP's SMEs are operating under a partnership and sole proprietor. The nature of firms operating in Hayatabad and Hattar are mostly operating under a partnership constitute of $69.1 \%$.

The nature of business refers to the sector/industry to which a company belongs to. The recorded information shows that most firms are operating in the manufacturing business (55\%) and trading base company (45\%) in KP's SMEs.

Out of $100 \%, 12.8 \%$ of in KP's SMEs are operational, less than a year, $29.3 \%$ are 1 to 5 years, $43.7 \%$ are between 6 to 10 years and above 10 years are $14.2 \%$. Firms with less than 50 employees are considered small enterprises and More than 50 and less than 250 employees are considering medium enterprises. The recorded information shows that most of the SMEs are small enterprises (65.9\%) in Hayatabad and Hattar as compare to medium enterprises (35.1\%).

\section{Frequency Distribution of Investment Decision in KP's SMEs}

The investment decision is the dependent variable. Firms made any investment in the last three years are considered "Yes" and if no investment in the last three years is considered "No". The investment decision relates to the decision made by the investors or the top-level management concerning the amount of funds to be deployed in the investment opportunities. 
Table 3: Frequency Distribution of Investment Decisions

\begin{tabular}{|lll|}
\hline Investment Decision & Frequency & Percentage \\
\hline No & 31 & 12.4 \\
Yes & 218 & 87.6 \\
Total & 249 & 100.0 \\
\hline
\end{tabular}

Table 3 shows that most of the investors invested in the last three years. This clearly shows that probability of investing, in general, is very high (0.876) and gives an overall Odd Ratio of $7.06(0.876 / .124=7.06)$ indicating that investing is about seven times greater than not invest.

\section{Impact of Confidence on Investment Decision in KP's SME}

The basics descriptive statistics of confidence (sub-factor psychological) are given. The purpose of the descriptive statistic is to describe the basic features of the randomly selected sample data of KP's SMEs.

Table4 Descriptive Statistics of Confidence [ $\mathrm{n}=249]$

\begin{tabular}{|llllllll|}
\hline $\begin{array}{l}\text { Sub-Factors } \\
\text { Confidence }\end{array}$ & Mean & $\begin{array}{l}\text { Std. } \\
\text { Deviation }\end{array}$ & Strongly Agree & Agree & Neutral & Disagree & $\begin{array}{l}\text { Strongly } \\
\text { Disagree }\end{array}$ \\
\hline CON1 & 4.48 & 1.11 & $185(74.2 \%)$ & $37(14.8 \%)$ & $5(2.1 \%)$ & $5(2.0 \%)$ & $17(6.8 \%)$ \\
CON2 & 3.54 & 1.23 & $54(21.7 \%)$ & $109(43.8 \%)$ & $22(8.8 \%)$ & $45(18.1 \%)$ & $19(7.6 \%)$ \\
CON3 & 4.36 & 1.08 & $168(67.5 \%)$ & $32(12.9 \%)$ & $28(11.2 \%)$ & $13(5.2 \%)$ & $8(3.2 \%)$ \\
CON4 & 4.29 & 1.16 & $158(63.5 \%)$ & $49(19.7 \%)$ & $10(4.1 \%)$ & $20(8.0 \%)$ & $12(4.8 \%)$ \\
CON5 & 4.43 & 1.05 & $166(66.7 \%)$ & $57(22.9 \%)$ & $8(3.2 \%)$ & $3(1.2 \%)$ & $15(6.0 \%)$ \\
CON6 & 3.78 & 1.11 & $81(32.5 \%)$ & $78(31.3 \%)$ & $51(20.6 \%)$ & $33(13.3 \%)$ & $6(2.4 \%)$ \\
*CON.COM & 4.15 & 1.12 & $135.3(54.3 \%)$ & $60.3(24.2 \%)$ & $20.6(8.3 \%)$ & $19.8(8.0 \%)$ & $12.8(5.2 \%)$ \\
\hline
\end{tabular}

*CON.COM is an average of all sub-factors (CON1 to CON6).

Table 4 illustrates the outcomes of descriptive statistics of confidence. The mean value of "outperforming business skills motivate (CON1)" is recorded 4.48 with a standard deviation of 1.11, which shows the very high impact and on the average minimum variation from its mean value. It can assume that selected investors responses are more similar to each other because the mean value of all variables are lies between 3 to 4 shows that have a high impact of investment decision and standard deviation also lies around 1 also shows the less average minimum variation. Similarly, the frequencies of confidence are also observed the high percentage for strongly agree/agree with which suggest that these sub-factors have high impact. Overall majority of $195.6(78.5 \%)$ respondents have strongly agreed/agreed and consider it as motivational factors in the investment decision. There are 32.6 (13.2\%) respondents do not agree and few 20.6 (8.3\%) respondents were natural regarding confidence as motivational factor. It can be concluded that the mean value for overall confidence is observed 4.15 lies between 4 to 5 indicates that overall confidence has a high impact on investors' investment decisions and frequencies also supported the by showing strongly agree and agree with concern on confidence motivation factor in KP's SMEs.

\section{Impact of Optimism on Investment Decision in KP's SME}

Table 5: Descriptive Statistics of Optimism (OPT) [n=249]

\begin{tabular}{|llllllll|}
\hline $\begin{array}{l}\text { Sub-Factors of } \\
\text { Optimism }\end{array}$ & Mean & $\begin{array}{l}\text { Std. } \\
\text { Deviation }\end{array}$ & $\begin{array}{l}\text { Strongly } \\
\text { Agree }\end{array}$ & Agree & Neutral & Disagree & $\begin{array}{l}\text { Strongly } \\
\text { Disagree }\end{array}$ \\
\hline OPT1 & 3.9 & 1.2 & $108(43.4 \%)$ & $66(26.4 \%)$ & $24(9.7 \%)$ & $47(18.8 \%)$ & $4(1.6 \%)$ \\
OPT2 & 3.8 & 1.4 & $119(47.8 \%)$ & $42(16.9 \%)$ & $28(11.2 \%)$ & $44(17.7 \%)$ & $16(6.4 \%)$ \\
OPT3 & 4.4 & 1.1 & $168(67.4 \%)$ & $32(12.9 \%)$ & $28(11.3 \%)$ & $13(5.2 \%)$ & $8(3.2 \%)$ \\
OPT4 & 3.9 & 1.3 & $113(45.4 \%)$ & $49(19.7 \%)$ & $35(14.0 \%)$ & $41(16.5 \%)$ & $11(4.4 \%)$ \\
*OPT.COM & 4 & 1.25 & $127(51.2 \%)$ & $47.2(19 \%)$ & $28.8(11.6 \%)$ & $36.2(14.5)$ & $9.2(3.7 \%)$ \\
\hline
\end{tabular}

*OPT.COM is an average of all sub-factors (OPT1 to OPT4). 
Table 5 shows the results of the mean value for sub-factors "you are usually able to anticipate the trends of the market (OPT3)" is observed 4.4 with standard deviation value 1.1 which indicates high impact and on the average. Similarly, for other sub-factor, the mean values are observed between 3 and 4 , which suggest that these sub-factors have high impact. The mean value for overall optimism is recorded 4.0 with on average variation 1.2 lies between 3 to 4 , suggesting that overall optimism have a high impact on investment decisions. The frequencies of these respondents show that the majority of respondents have shown their concern by agreeing with these sub motivating factors. Overall, 174.4 (70.2\%) have strongly agreed/agreed and very few of $28.8(11.6 \%)$ respondents are neutral. There were some respondents, 45.4 $(18.2 \%)$ have shown adverse concern and do not agree with these sub-factors of optimism.

\section{Impact of Loss Aversion (LA) on Investment Decision in KP's SMEs}

Table 6: Descriptive Statistics of Loss Aversion (LA) [n=249]

\begin{tabular}{|llllllll|}
\hline $\begin{array}{l}\text { Sub-factors } \\
\text { of } \begin{array}{l}\text { Loss } \\
\text { aversion }\end{array}\end{array}$ & Mean & $\begin{array}{l}\text { Std. } \\
\text { Deviation }\end{array}$ & $\begin{array}{l}\text { Strongly } \\
\text { Agree }\end{array}$ & Agree & Neutral & Disagree & $\begin{array}{l}\text { Strongly } \\
\text { Disagree }\end{array}$ \\
\hline LA1 & 4 & 0.9 & $77(30.9 \%)$ & $124(49.8 \%)$ & $24(9.6 \%)$ & $23(9.2 \%)$ & $1(0.4 \%)$ \\
LA2 & 3.8 & 1.1 & $86(34.5 \%)$ & $70(28.1 \%)$ & $56(22.5 \%)$ & $28(11.2 \%)$ & $9(3.6 \%)$ \\
LA3 & 3.4 & 1.2 & $70(28.1 \%)$ & $42(16.9 \%)$ & $69(27.7 \%)$ & $62(24.9 \%)$ & $6(2.4 \%)$ \\
LA4 & 3.3 & 1.3 & $57(22.9 \%)$ & $70(28.1 \%)$ & $35(14.1 \%)$ & $67(26.9 \%)$ & $20(8.0 \%)$ \\
*LA.COM & 3.6 & 1.1 & $72.5(29.1 \%)$ & $76.5(30.6 \%)$ & $46(18.6 \%)$ & $45(18.1 \%)$ & $9(3.6 \%)$ \\
\hline
\end{tabular}

*LA.COM is an average of all Sub-factors (LA1 to LA4).

Table 6 shows the results of the mean value for sub-factors, "you are very careful while investing (LA1)" shows the mean value of 4.0 with a small standard deviation of 0.9 shows that LA1 has a very high impact on investment decision. Similarly, for other sub-factor, the mean values are observed between 3 and 4 , which suggest that these sub-factors have high impact. The frequency of LA1 shows that 201 (80.7\%) respondents have shown positive response by considering it as a motivating sub-factors and very few have $24(9.6 \%)$ shown adverse concern. It can be concluded from the table that all sub-factors of LA have a significant impact on investment decision because their means value is lies between 3.3 and 4.0 and overall as an average of $149(59.7 \%)$ respondents have shown the strongly agreed/agreed concern for LA.

\section{Impact of Herd Behaviour (HB) on investment decisions in KP's SMEs}

Table 7: Descriptive Statistics of Herd Behaviour (HB) [n=249]

\begin{tabular}{|c|c|c|c|c|c|c|c|}
\hline $\begin{array}{l}\text { Sub-factors of } \\
\text { Herd } \\
\text { Behaviour }\end{array}$ & $\begin{array}{l}\text { Mea } \\
\text { n }\end{array}$ & $\begin{array}{l}\text { Std. } \\
\text { Deviatio } \\
\text { n }\end{array}$ & $\begin{array}{l}\text { Strongly } \\
\text { Agree }\end{array}$ & Agree & Neutral & Disagree & $\begin{array}{l}\text { Strongly } \\
\text { Disagree }\end{array}$ \\
\hline HB1 & 3.9 & 1 & $68(27.3 \%)$ & $113(45.4 \%)$ & $39(15.6 \%)$ & $22(8.9 \%)$ & $7(2.8 \%)$ \\
\hline HB4 & 3.6 & 1.3 & $58(23.3 \%)$ & $81(32.5 \%)$ & $67(27 \%)$ & $31(12.4 \%)$ & $12(4.8 \%)$ \\
\hline $\mathrm{HB} 2$ & 3.6 & 1.1 & $59(23.7 \%)$ & $66(26.5 \%)$ & $41(16.4 \%)$ & $80(32.2 \%)$ & $3(1.2 \%)$ \\
\hline HB3 & 3.4 & 1.2 & $78(31.3 \%)$ & $70(28.1 \%)$ & $41(16.5 \%)$ & $44(17.7 \%)$ & $16(6.4 \%)$ \\
\hline HB5 & 3.2 & 1 & $23(9.2 \%)$ & $77(30.9 \%)$ & $80(32.2 \%)$ & $66(26.5 \%)$ & $3(1.2 \%)$ \\
\hline HB COM* & 3.5 & 1.1 & $57.2(23.0 \%)$ & $81.4(32.7 \%)$ & $53.6(21.5 \%)$ & $48.6(19.5 \%)$ & $8.2(3.3 \%)$ \\
\hline
\end{tabular}

*HB.COM is an average of all sub-factors (HB1 to HB5).

Table 7 shows the mean value 3.9 for "other investor's decisions have an influence (HB1)" with a standard deviation of 1.0, which shows the high impact of HB1 on investment decision. The frequency for HB1 shows that $181(72.7 \%)$ respondents have strongly agreed/agreed with HB1 and considering it as a motivating factor in investment and very few $29(11.7 \%)$ respondents have shown adverse concern. It can be concluded from the table that sub-factors of HB have a substantial impact on investment as their mean is high and overall frequencies of HB shows that 138.6 (55.7\%) respondents have agreed and considered it as a motivating factor in the investment decision. 


\section{Binary Logistic Regression Model}

The binary logistic regression is as a dependent variable has only two possibilities, i.e. Yes (1) and No (0). The psychological variables of the study include confidence, optimism, loss aversion and herd behaviour. These all are calculated through arithmetic mean based on selected sub-factors. Our logistic model is determined as:

$$
\log \left[P_{\text {investment }}\left(1-P_{\text {no investment }}\right)\right]=\alpha+\beta i X i \ldots E q . \text { (1) }
$$

In the above equation, $\mathrm{P}$ make an investment is the probability of those respondents who made an investment, 1-P does not make an investment is the probability of those respondents who do not make an investment while $\log [$ Pmake investment/(1-Pdoes not make an investment)] shows odds. The econometric form of the model is given below in Equation 2.

$$
\text { INVD }=\alpha+\beta_{1} \text { CON.Com }+\beta_{2} \text { OPT.Com }+\beta_{3} \text { LA.Com }+\beta_{4} \text { HB.Com }+e \ldots E q . \text { (2) }
$$

\begin{tabular}{|c|c|c|c|c|c|c|c|}
\hline Variables & B & S.E. & Wald & df & & Sig. & Odds Ratio \\
\hline CON.COM & 1.385 & 0.41 & 11.39 & 1 & & 0.001 & 3.9 \\
\hline OPT.COM & 2.095 & 0.597 & 12.32 & 1 & & 0.000 & 8.1 \\
\hline LA.COM & 0.62 & 0.542 & 1.309 & 1 & & 0.253 & 1.8 \\
\hline HB.COM & 2.027 & 0.677 & 8.962 & 1 & & 0.003 & 7.6 \\
\hline Constant & -18.09 & 4.031 & 20.14 & 1 & & & \\
\hline$-2 \quad \log$ & $\operatorname{Cox} \&$ & Snell & Nagelkerk & & $\mathbf{R}$ & & \\
\hline likelihood & Square & & Square & & & Chi-square & Sig. \\
\hline
\end{tabular}

Table 8: Estimated Coefficients

CON.COM, OPT.COM, LA.COM, HB.COM are the averages of Sub-factors of psychological

Table 8 describes the results of the model defined in Eq. (2), which includes logistic regression coefficients their standard error, Wald test, significance level and odds ratio (OR). Estimated results of defined model illustrate that the selected motivating factors of CON.COM, OPT.COM, LA.COM and HB.COM have positive impacts on investor's investment decisions as all of the estimated values of regression parameters are recorded positive. The statistical significance and insignificance of the estimated regression coefficient for the selected motivating factors were observed based on the Wald test and significance level. The calculated Wald test values for all the factors are recorded large except LA.COM and their significance level are recorded less than 0.05 shows that the factors have a significant impact on investors investment decision. The standard errors are lies below 1 which is very low. Furthermore, the selected factors show a remarkable impact on investment decisions based on odd ratios. Estimated values of the odd ratio of investing in the presence of motivating factors of CON.COM, OPT.COM, FL.COM and HB.COM were recorded more than one for each psychological factor with odd's probabilities above $50 \%$ shows the influence on the investor's investment decision. These OR shows that the probability of making an investment is high as compared to not investing in the presence of these factors.

The estimated model summary based on performance through likelihood ratio test (-2 Log-likelihood) and two type's pseudo coefficient of determination (R-Square) used to measure the explained variation in the fitted model based on selected independent variables. The value of Cox \& Snell R-Square $=0.410$ and Nagelkerke R-Square $=0.775$ are recorded, indicates that $41 \%$ and $77.5 \%$ variation is explained in investment decision based on selected independent variables, which are quite good and the remaining unexplained variation is based on some others variables not considered in this study. Furthermore, the observed value of -2 Log-likelihood $=55.871$ the minimum value of this statistic indicting the model is best fitted to the data. 
Estimated Model Correctness

Table 9: Classification Table

\begin{tabular}{|c|c|c|c|c|}
\hline \multicolumn{2}{|l|}{ Observed } & \multicolumn{3}{|c|}{ Predicted } \\
\hline \multirow{5}{*}{$\begin{array}{l}\text { Did you make any investment } \\
\text { In the last three years } \\
\text { Overall Percentage }\end{array}$} & \multirow{4}{*}{$\begin{array}{l}\text { No } \\
\text { Yes }\end{array}$} & \multirow{2}{*}{\multicolumn{2}{|c|}{$\begin{array}{l}\text { Did you make any } \\
\text { the last three years } \\
\text { No } \quad \text { Yes }\end{array}$}} & ${ }^{n}$ Percentage Correct \\
\hline & & & & \\
\hline & & 24 & 7 & 77.4 \\
\hline & & 3 & 215 & 98.6 \\
\hline & & & & 96.0 \\
\hline
\end{tabular}

Table 9 illustrates the results classification table, which is a method to assess the predictive accuracy of the logistic model. The results show observed values of dependent variable outcome and predicted values at a cut-off value $\mathrm{P}=0.50$. From the table, it can be observed that the model correctly predicts $96 \%$ of the cases.

\section{Best Estimated Logistic Model of Psychological Variables}

Table 10: Model Summary

\begin{tabular}{|cccc|}
\hline Step & -2 Log likelihood & Cox \& Snell R Square & Nagelkerke R Square \\
\hline 1 & 94.981 & 0.309 & 0.585 \\
2 & 68.951 & 0.378 & 0.715 \\
3 & 57.200 & 0.407 & 0.769 \\
\hline
\end{tabular}

Table 10 shows the results of three steps as the best model are selected in step three. At step three the value of Cox \& Snell R-Square $=0.407$ and Nagelkerke R-Square $=0.769$ were recorded, indicates that $40.7 \%$ and $76.9 \%$ variation is explained in investors investment decision based on selected independent variables. Furthermore, FL.COM is removed as it indicates that it is not playing a vital role in the model.

Table 11: Estimated Coefficients

\begin{tabular}{|lllllll|}
\hline Variables & & B & S.E. & Wald & Sig. & Exp(B) \\
\hline \multirow{2}{*}{ Step $1^{\mathrm{a}}$} & CON.COM & 2.211 & 0.315 & 49.367 & 0.000 & 9.122 \\
& Constant & -5.885 & 1.074 & 30.014 & 0.000 & .003 \\
& CON.COM & 1.328 & .354 & 14.038 & 0.000 & 3.774 \\
Step $2^{\text {b }}$ & OPT.COM & 2.312 & .547 & 17.844 & 0.000 & 10.093 \\
& Constant & -10.493 & 1.896 & 30.643 & 0.000 & .000 \\
& CON.COM & 1.487 & .396 & 14.097 & 0.000 & 4.423 \\
Step $3^{\text {c }}$ & OPT.COM & 2.187 & 0.589 & 13.760 & 0.000 & 8.905 \\
& HB.COM & 1.741 & 0.577 & 9.113 & 0.003 & 5.705 \\
& Constant & -15.860 & 3.128 & 25.709 & 0.000 & 0.000 \\
\hline
\end{tabular}

Table 11 shows the best model selected in step three includes three variables CON.COM, OPT. COM and HB.COM have a significant influence on investor's investment decisions. The influence of CON.COM, OPT.COM and HB.COM on investor's investment decision is positive.

The OR shows that the presence of these three sub motivating factors of psychological have maximum chance to invest in SMEs. The estimated best model is obtained of a defined model at step three with three sub motivating psychological factors from four which are CON.COM, OPT.COM, and HB.COM. 
Estimated Best Model Correctness

Table 12: Classification Table

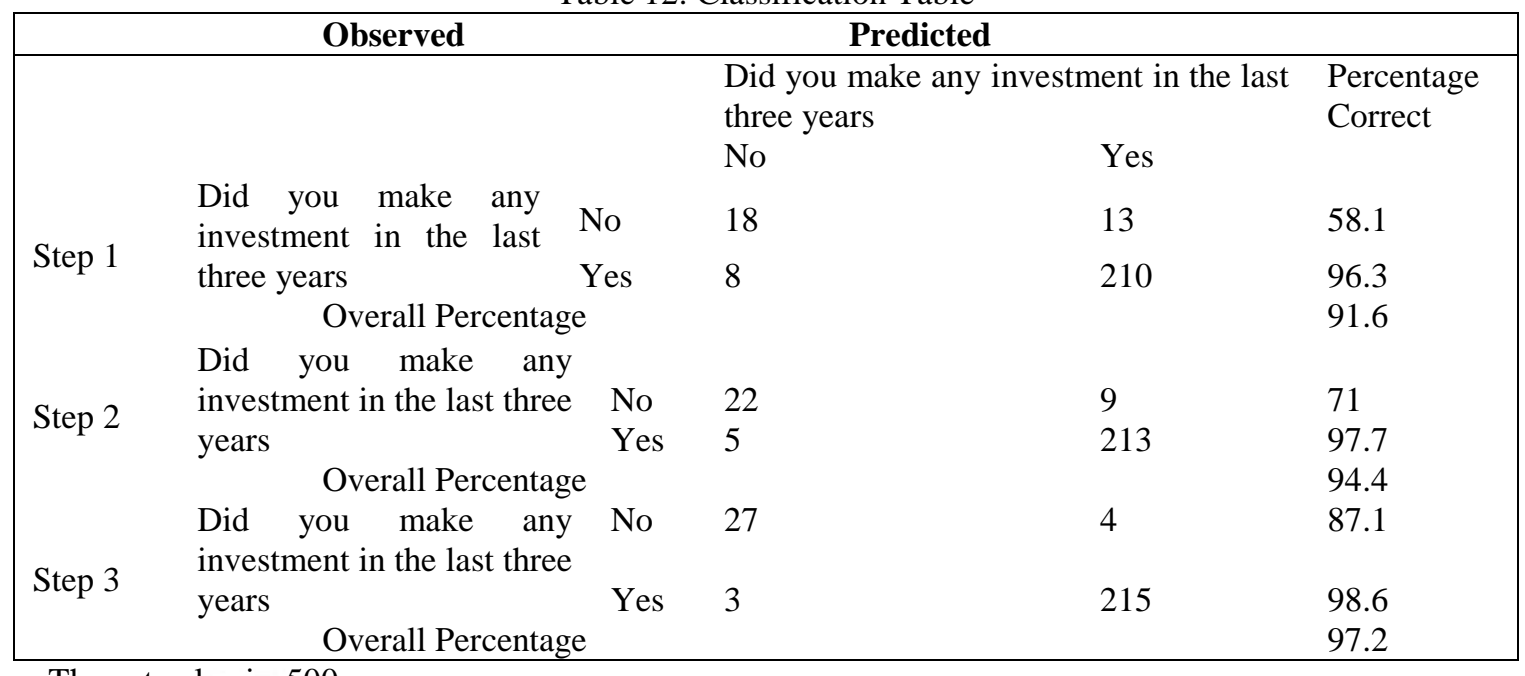

a. The cut value is .500

Table 12 illustrates the results classification table for both models presents in step one two and three, which is a method to assess the predictive accuracy of the logistic model. The results show observed values of dependent variable outcome and predicted values at a cut-off value $\mathrm{P}=0.50$. From the table, it can be observed that model in step one correctly predicts $91.6 \%$ of the model, at step two predicts $94.4 \%$ of the model and at step 3 correctly predicts $97.2 \%$ of the model correctness.

\section{Discussion and Conclusion}

Previously there was not the specific study was present which can identify the on the psychological, motivational factors in investment decision in the promotion of SMEs. Waweru, Munyoki, \& Uliana (2008) suggested that investment decision is influenced in a large proportion by psychological and emotional factors. There was evidence that psychological factors affect the investment decision in context to stock market. This study has taken this relation in context to SMEs. The odds ratio implies that investing in the presence of confidence is 3.9 times more than the odds of not investing in the presence of confidence. The p-value is less than $5 \%$. The research hypothesis $\left(\mathrm{H}_{1}\right)$ is accepted and rejected the null hypothesis. The result is consistent with Faris (2019) as confidence is essential factors while making investment and if the investor is highly confidence trends towards invest. Optimism influenced the investment decision of KP's investors as the coefficient is positive and the odd of investors having an investment is 8.1 times more in the absence of optimism and its result is statistically significant. The study accepted the research hypothesis $\left(\mathrm{H}_{2}\right)$ as results are consistent with (Huang et al., 2018). The research hypothesis is accepted and rejected the null hypothesis. Loss aversion has a positive insignificantly relationship with investment decisions, which means one unit increase in loss aversion will cause an increase of 0.62 units but the relation is not statistically significant; however, the odds investing in KP's SMEs is more than 1 than the odds of not investing in the presence of loss aversion. The results are consistent with (Richard, 2002; Sarwar \& Afaf, 2016) which mentioned that investors behave irrationally because they are afraid of losses in future and influence the decision making. The research hypothesis $\left(\mathrm{H}_{3}\right)$ is accepted and rejected the null hypothesis. Herd behaviour has a positive and significant relationship with investment decision and the odds of investing in the presence of herd behaviour is 7.6 time of not making an investment in the presence of herd behaviour. The results are consistent with (Abul, 2019) but inconsistent with (Ton \& Dao, 2014). The research hypothesis $\left(\mathrm{H}_{4}\right)$ is accepted and rejected the null hypothesis, which reflects that herd behaviour is essential factors in influencing investment decisions. All authors have taken psychological factors with 
investment decisions in the stock market; however, our study has taken the same variable but in SMEs sectors. Irrespective of the different dynamic between the stock market and SME but the psychological factors have the same pattern while making investment decisions.

\section{Recommendation}

The study is related to the psychological factors that influence investment decisions in KP's SMEs. However, it can be recommended that this study should be taken to all provinces and consider other motivational factors such as economic factors, financial factors and government factor in order to reflect a broader view so investors should be encouraged in order to prevail the growth of SMEs and ultimately will lead to employment and prosperity. The findings of this study could help academia as a whole by adding new knowledge to the field of finance and behavioural finance which is still a niche for finance scholar in Pakistan. Furthermore, comparative studies are suggested between different industrial zones.

\section{References}

Abul, S. J. (2019). Factors influencing individual investor behaviour: Evidence from the Kuwait stock exchange. Asian Social Science, 15(3), 27-39.

Ahmad, S. Z., Kassim, S. K. M., \& Rani, N. S. A. (2010). Business challenges and strategies for development of small and medium-sized enterprises (SMEs) in Malaysia. International Journal of Business Competition and Growth, 1(2), 177-197.

Alquraan, T., Alqisie, A., \& Shorafa, A. Al. (2016). Do behavioral finance factors influence stock investment decisions of individual investors? (evidences from Saudi stock market ). American International Journal of Contemporary Research, 6(3), 159-169.

Areiqat, A. Y., Abu-rumman, A., Al-alani, Y. S., \& Alhorani, A. (2019). Impact of behavioral finance on stock investment decisions applied study on a sample of investors at Amman stock exchange. Academy of Accounting and Financial Studies Journal, 23(2), 1-17.

Bakara, S., \& Yia, A. N. C. (2016). The impact of psychological factors on investors' decision making in the impact of psychological factors on investors' decision making in Malaysian stock market: A Case of Klang Valley and Pahang. Procedia Economics and Finance, 35, 319-328.

Bashir, T., Azam, N., Butt, A. A., Javed, A., \& Tanvir, A. (2013). Are behavioral biases influenced by demographic characteristics \& personality traits? Evidence from Pakistan. European Scientific Journal, 9(70), 277-293.

Bikhchandani, S., \& Sharma, S. (2001). Herd behavior in financial markets. International Monetary Fund Staff Papers, 47(3), 279-310.

Boda, J. R., \& Sunitha, S. (2018). Investor's psychology in investment decision making: A behavioral finance approach. International Journal of Pure and Applied Mathematics, 119(7), 1253-1261.

Chen, I., \& Lin, S. (2013). Managerial optimism, investment efficiency and firm valuation. Multinational Finance Journal, 17(3), 295-340

Cochran, W. (1963). Sampling Technique (2nd Edition). New York: John Wiley and Sons Inc.

Coval, J., \& Thakor, A. (2005). Financial intermediation as a beliefs-bridge between optimists and pessimists. Journal of Financial Economics, 75(3), 535-569.

Cronbach, L. J. (1951). Coefficient alpha and the internal structure of tests. Psychometrika, 16, $297-334$.

Dar, M. S., Ahmed, S., \& Raziq, A. (2017). Small and medium-size enterprises in pakistan: Definition and critical issues. Pakistan Business Review, 19(1), 46-70.

Faris, A. (2019). The effect of overconfidence over optimism and herding on investment decision making. 10, 104-126.

Gakhar, D. (2019). Role of optimism bias and risk attitude on investment behaviour. Theoretical Economics Letters, 9, 852-871.

Gervais, S., Heaton, J. B., \& Odean, T. (2002). The positive role of overconfidence and optimism in investment policy. Rodney L White Center For Financial Research, Working Papers.

Gill, S., Khurshid, M. K., Mahmood, S., \& Ali, A. (2018). Factors effecting investment decision making 
behavior: the mediating role of information searches. European Online Journal of Natural and Social Sciences, 7(4), 758-767.

Gveroski, M., \& Jankuloska, R. A. (2017). Determinants of investment decisions in smes. Balkan and Near Eastern Journal of Social Sciences, 3(1), 71-78.

Ghelichi, M. A., Nakhjavan, B., \& Gharehdaghi, M. (2016). Impact of psychological factors on investment. Asian Journal of Management Sciences \& Education, 5(3), 36-44.

Hassan, T. R., Khalid, W., \& Habib, A. (2014). Overconfidence and loss aversion in investment decisions:A study of the impact of gender and age in pakistani perspective. International SAMANM Journal of Finance and Accounting. 2(3), 148-158.

Hirt, G., \& Block, S. (2012). Fundamentals of investment management (10th ed.). New York: McGrawHill.

Hong, H., \& Stein, J. . (1999). A unified theory of underreaction, momentum trading, and overreaction in asset markets. The Journal of Finance, 54(6), 2143-2184.

Huang, R., Jui, K., Tan, K., Sulaeman, J., \& Faff, R. (2018). Optimism or over-precision? What drives the role of overconfidence in managerial investment decisions?. Mimeo, University of Queensland.

Iqbal, N. (2015). Impact of optimism bias on investment decision: evidence from Islamabad stock exchange, Pakistan. Research Journal of Finance and Accounting, 6(19), 74-79.

Kabra, G., Mishra, P., \& Dash, M. (2010). Factors influencing investment decision of generations in India: An econometric study. Asian Journal of Management Research, 4, 305-326.

Kadiri, I. B. (2012). Small and medium scale enterprises and employment generation in Nigeria: The role of finance. Arabian Journal of Business and Management Review, 1(9), 79-93.

Kafayat, A. (2014). Interrelationship of biases: effect investment decisions ultimately. Theoretical and Applied Economics, 21(6), 85-110.

Kahneman, D., \& Tversky, A. (1979). Prospect theory: An analysis of decision under risk. Econometrica, 47(2), 263-291.

Kengatharan, L., \& Kengatharan, N. (2014). The influence of behavioural factors in making investment decisions and performance: Study on investors of Colombo stock exchange, Sri Lanka. Asian Journal of Finance \& Accounting, 6(1), 2-23.

Khalique, M., Isa, A. H. B. M., Shaari, J. A. N., \& Ageel, A. (2011). Challenges faced by the small and medium enterprises (smes) in Malaysia: An intellectual capital perspective. International Journal of Current Research, 3(6), 398-402.

Kisaka, E. K. (2015). The effect of behavioral finance factors on stock investment decisions in Kenya. Master of Business Administration of South Eastern Kenya University.

Kuratko, D. F., Hornsby, J. S., \& Naffziger, D. W. (1997). An examination of owner's goals in sustaining entrepreneurship. Journal of Small Business Management, 35(1), 25-30.

Lim, L. C. (2012). The relationship between psychological biases and the decision making of investor in Malaysian share market. In Unpublished Paper International Conference on Management, Economics \& Finance (ICMEF 2012) Proceeding.

Luong, L. P., \& Ha, D. T. T. (2011). Behavioral factors influecing individual investors' decision -making and performance: A survey at he ho chi minh stock exchange. Umeå School of Business.

Millinuex, A. W. (1997). The funding of non-financial corporations (NFCs) in the EU (1971-1993): Evidence of convergence. University of Birmingham, Birmingham.

Mukhtar, T. (2018). Confronting economic challenges-iv: the power of sme sector. Published in Daily Times, 3rd October 2018.

Nichter, S., \& Goldmark, L. (2009). Small firm growth in developing countries. World Development, 37(9), $1453-1464$.

Hoffmann, A. O. I., and Post, T. (2016). How does investor confidence lead to trading? Linking investor return experiences, confidence, and investment beliefs. Journal of Behavioral and Experimental Finance, 12(1), 65-78.

Puri, M., \& Robinson, D. T. (2007). Optimism and economic choice. Journal of Financial Economics, 86(1), 71-99.

Qadri, S. U., \& Shabbir, M. (2014). An empirical study of overconfidence and illusion of control biases, 
impact on investor's decision making: An evidence from ISE. European Journal of Business and Management, 6(14), 38-44.

Qureshi, S. A., Rehman, K. ur, \& Hunjra, A. I. (2014). Factors affecting investment decision making of equity fund managers factors affecting investment decision making of equity fund managers. Wulfenia Journal, 19(10), 280-291.

Riaz, L., \& Ahmed. (2015). Relationship between psychological factors and investment decision making: The mediating role of risk perception. Pakistan Journal of Commerce and Social Sciences, 9(3), 968981.

Riaz, L., Hunjra, A. I., \& Azam, R. (2012). Impact of psychological factors on investment decision making mediating by risk perception: A conceptual study. Middle-East Journal of Scientific Research, 12, 789-795.

Richard, N. A. (2002). Individual investments behaviour. New York,: McGraw-Hill.

Ritter, J. R. (2003). Behavioral finance. Pacific-Basin Finance Journal, 11(4), 429-437.

Robichaud, Y., McGraw, E., \& Roger, A. (2001). Toward the development of a measuring instrument for entrepreneurial motivation. Journal of Developmental Entrepreneurship, 6(1), 189-202.

Rohra, C., \& Panhwar, I. (2009). The role of smes towards exports in Pakistan economy. Australian Journal of Basic and Applied Sciences, 3(2), 1070-1082.

Sarwar, A., \& Afaf, G. (2016). A comparison between psychological and economic factors affecting individual investor's decision-making behavior. Cogent Business and Management, 3(1).1-18.

Schlogl, H. (2004). Small and medium enterprises seizing the potential. Organisation for Economic Cooperation and Development. The OECD Observer, No. 243: 46-48.

Shalom, G. R. (2013). Effects of level of investors confidence and herding behavior on stock prices and their volatilities. Quarterly Journal of Economics, 26(11), 1-53.

Ton, H. T. H., \& Dao, T. K. (2014). The effects of psychology on individual investors' behaviors: Evidence from the Vietnam stock exchange. Journal of Management and Sustainability, 4(3), 125-134.

Wamae, N. J. (2013). Behavioural factors influencing investment decision in stock market: A survey of investment banks in Kenya. International Journal of Social Sciences and Entrepreneurship, 1(6), 6883.

Waweru, N. M., Munyoki, E., \& Uliana, E. (2008). The effects of behavioral factors in investment decision-making: A survey of institutional investors operating at the Nairobi stock exchange. International Journal of Business and Emerging Markets, 1(1), 24-41.

Zafar, A., \& Mustafa, S. (2017). Smes and its role in economic and socio-economic development of Pakistan. International Journal of Academic Research in Accounting, Finance and Management Sciences, 7(4), 1-16. 


\section{Annexure 1}

Exploratory Factor Analysis of Psychological Factor

\begin{tabular}{|l|l|l|l|l|}
\hline \multicolumn{5}{|l|}{ Psychological Sub-Factors } \\
\hline Variables & Confidence & Optimism & Loss Aversion & Herd Behaviour \\
\hline CON1 & 0.841 & & & \\
\hline CON2 & 0.638 & & & \\
\hline CON3 & 0.650 & & & \\
\hline CON4 & 0.566 & & & \\
\hline CON5 & 0.716 & & & \\
\hline CON6 & 0.706 & & & \\
\hline OPT1 & & 0.737 & & \\
\hline OPT2 & & 0.627 & & \\
\hline OPT3 & & 0.833 & & \\
\hline OPT4 & & 0.509 & & \\
\hline LA1 & & & 0.579 & \\
\hline LA2 & & & 0.652 & \\
\hline LA3 & & & 0.851 & \\
\hline LA4 & & & 0.578 & \\
\hline HB1 & & & & 0.723 \\
\hline HB2 & & & & 0.754 \\
\hline HB3 & & & & 0.583 \\
\hline HB4 & & & & 0.431 \\
\hline HB5 & & & & 0.418 \\
\hline
\end{tabular}

